\title{
Effects of diammonium glycyrrhizinate on random skin flap survival in rats: An experimental study
}

\author{
QING-BO LV, XIANG GAO, DING-SHENG LIN, YUN CHEN, BIN CAO and KAI-LIANG ZHOU \\ Department of Hand and Plastic Surgery, The Second Affiliated Hospital of Wenzhou Medical University, \\ The Second Clinical Medical College of Wenzhou Medical University, Wenzhou, Zhejiang 325027, P.R. China
}

Received April 4, 2016; Accepted July 15, 2016

DOI: $10.3892 /$ br.2016.733

\begin{abstract}
Partial necrosis of skin flaps continues to restrict the survival of local skin flaps following plastic and reconstructive surgeries. The aim of the present study was to investigate the effects of diammonium glycyrrhizinate (DG), a salt of glycyrrhetinic acid that has been widely used in the therapy of chronic hepatitis and human immunodeficiency virus infection, on random skin flap survival in rats. McFarlane flaps were established in 60 male Sprague-Dawley rats randomly divided into three groups. Group I served as the control group and was injected with saline $(10 \mathrm{mg} / \mathrm{kg})$ once per day. Group II and group III were the experimental groups, and were injected with $10 \mathrm{mg} / \mathrm{kg}$ DG once and twice per day, respectively. On day 7 , the survival area of the flap was measured. Tissue samples were stained with hematoxylin and eosin and immunohistochemically evaluated. Tissue edema, neutrophil density, superoxide dismutase (SOD) activity and malondialdehyde (MDA) levels were evaluated. The mean survival areas of the flaps of group II were significantly larger when compared with those of group I $(\mathrm{P}<0.05)$, and the rats of group III exhibited significantly higher survival areas than group II $(\mathrm{P}<0.05)$. Histologic and immunohistochemical evaluation showed that microvessel development and the expression level of vascular endothelial growth factor were higher in the two experimental groups than in the control group. Furthermore, SOD activity was significantly increased $(\mathrm{P}<0.05)$, while the neutrophil density and MDA level were significantly reduced $(\mathrm{P}<0.05)$ in group II when compared with group I. Significant differences between group II and group III with regard to SOD activity
\end{abstract}

Correspondence to: Dr Ding-Sheng Lin, Department of Hand and Plastic Surgery, The Second Affiliated Hospital of Wenzhou Medical University, The Second Clinical Medical College of Wenzhou Medical University, 109 XueYuan Xi Road, Wenzhou, Zhejiang 325027, P.R. China

E-mail: lindingsheng@gmail.com

Key words: diammonium glycyrrhizinate, random flap survival, inflammation, vascular endothelial growth factor, ischemia-reperfusion injury and MDA level were also observed $(\mathrm{P}<0.05)$. Thus, DG may have a dose-dependent effect on promoting the survival of random skin flaps.

\section{Introduction}

Transplantation and reconstruction of local skin flaps is the common surgical therapeutic strategy for soft tissue defects caused by trauma or tumor-resection. However, partial necrosis of the skin flaps restricts the survival of local skin flaps. These factors, including deficiency of blood perfusion, ischemia-reperfusion injury and expression of inflammatory factors, have been proven to contribute to partial skin necrosis (1). To enhance the survival of the local skin flap, it is crucial to improve the tolerance of the tissue to ischemia and inflammation, accelerate angiogenesis and alleviate tissue edema (2-4).

Diammonium glycyrrhizinate (DG) is a substance extracted from a traditional Chinese medical herb, Glycyrrhiza. Currently, DG is widely administered to patients with chronic hepatitis and human immunodeficiency virus infection for its anti-inflammatory, anti-viral and hepatoprotective effects $(5,6)$. A previous study in a model of ulcerative colitis indicated that DG was able to reduce inflammatory injury via suppression of nuclear factor $\kappa$-light-chain-enhancer of activated B cells $(\mathrm{NF}-\kappa \mathrm{B})$, tumor necrosis factor- $\alpha$ and intercellular adhesion molecule 1 , which are thought to promote inflammatory injury (7). Furthermore, it was found that DG had neuroprotective potential against ischemia-reperfusion injury in a model of focal cerebral ischemic-reperfusion injury, and this effect was also likely associated with the anti-inflammatory function of DG according to a previous study (8). However, the protective role of DG in random skin flap survival has not, to the best of our knowledge, been clearly characterized. In the current study, the effect of DG on random skin flap survival in rats was investigated.

\section{Materials and methods}

\section{Animal model and drug administration}

Ethics statement. The experiments of the current study were conducted in strict accordance with the guidelines from the National Institutes of Health and the Committee on Animal Research. Ketamine hydrochloride and xylazine hydrochloride 
were used in all surgical procedures. Animals were removed from the study and euthanized by an overdose of ketamine, and all efforts were made to minimize suffering.

Animals and materials. Sixty male Sprague-Dawley rats (weight, 250-300 g) were obtained from Wenzhou Medical University, Wenzhou, China [SCXK (Zhe) 2005-0019]. All rats were randomly divided into three groups, including one control group (group I) and two experimental groups (group II and group III). Each group contained 20 rats. A DG injection (H10940190) was purchased from Zhengda Tianqing Pharmacy Co., Ltd. (Lianyungang, China). Superoxide dismutase (SOD) and malondialdehyde (MDA) testing kits were purchased from Nanjing Jiancheng Biological Engineering Institute (Nanjing, China). Goat serum (SL038) was purchased from Solarbio Life Sciences Company (Beijing, China). Rat anti-vascular endothelial growth factor (VEGF) antibody (cat no. sc-53462) was purchased from Santa Cruz Biotechnology, Inc. (Dallas, TX, USA) and goat anti-rat IgG-R (ZDR-5307) was purchased from Zhongshan Golden Bridge Biotechnology, Co., Ltd. (Beijing, China).

Flap model and experimental design. The rats were anesthetized with an intraperitoneal injection of $50 \mathrm{mg} / \mathrm{kg}$ ketamine hydrochloride (Ketalar, Eczacibası, Turkey) and $5 \mathrm{mg} / \mathrm{kg}$ xylazine (Rompun; Bayer AG, Berlin, Germany). After anesthesia, rats were placed in the prone position and the dorsal skin was shaved. A McFarlane flap (size, 9x3 cm) was created at the dorsum of each rat (9). After controlling any bleeding, the flap was immediately sutured to the original position with 4-0 running nylon sutures and a wedged-on cutting needle (Fig. 1) (10). The flap area was divided into three distinct zones of equal size: The proximal area (area I); the intermediate area (area II); and the distal area (area III). All surgical procedures were performed by one researcher and no rats died during surgery. Group II and group III received $10 \mathrm{ml} / \mathrm{kg}$ DG via intraperitoneal injection once and twice per day, respectively, for 7 days. The control group was injected with the same quantity of saline solution in the same way once per day during the experiment (11). All rats were housed in a environmentally controlled room at a temperature of $20-22^{\circ} \mathrm{C}$ under $12 \mathrm{~h}$ light/dark cycles. The rats were individually housed to prevent cannibalism or injury caused by normal socialization (12), and were fed standard rat chow and water ad libitum. Seven days later, the rats were sacrificed via ketamine overdose.

Macroscopic evaluation. On the seventh postoperative day, the survival area of each flap was photographed and differences between the two experimental groups and the control group in general appearance, color, texture and hair condition, and any differences were recorded. The images were analyzed using Image-Pro Plus v6.0 software (Media Cybernetics, Inc., Rockville, MD, USA).

Assessment of survival areas. To quantify the survival areas, the flaps were measured by superimposition of photographs onto graph paper. All the results were represented as a percentage of viable area calculated using the following formula: Extent of viable area $\left(\mathrm{mm}^{2}\right)$ x 100/total area (viable and ischemic; $\mathrm{mm}^{2}$ ).
Tissue edema measurements. The degree of tissue edema was evaluated by the percentage of water content (13). On the seventh postoperative day, the flap (taken immediately after the rats had been sacrificed) was weighed and dehydrated in an autoclave at $50^{\circ} \mathrm{C}$. The samples were weighed daily until the weight was constant for 2 days. The percentage water content of the tissue was determined by the following equation: Tissue water content $(\%)=[($ wet weight - dry weight $) /$ wet weight] x 100 .

Histology. On day 7, subsequent to the rats being euthanized, the flap tissues were harvested from each area and divided into three parts of equal size $(1 \mathrm{x} 1 \mathrm{~cm})$. All of the tissue specimens were fixed in $10 \%$ paraformaldehyde for $24 \mathrm{~h}$, embedded in paraffin and sectioned into 4- $\mu \mathrm{m}$ slices. According to the standard protocol, each section was stained with hematoxylin and eosin (H\&E). The microvessel number per unit area $\left(/ \mathrm{mm}^{2}\right)$ was then counted under a light microscope at a magnification of $x 200$ to establish the microvascular density (MVD). In addition, neutrophil infiltration was counted under a light microscope at a magnification of $\mathrm{x} 200$.

VEGF expression. The VEGF expression level was evaluated immunohistochemically by employing a streptavidin/peroxidase-based protocol. Firstly, the slides were blocked with normal goat serum at room temperature for $20 \mathrm{~min}$, and immersed in $50 \mu \mathrm{l}$ anti-VEGF antibody solution (diluted 1:100) at $4^{\circ} \mathrm{C}$ overnight. All slides were maintained at $37^{\circ} \mathrm{C}$ for $45 \mathrm{~min}$ and washed with phosphate-buffered saline (PBS). Then $50 \mu \mathrm{l}$ goat anti-rat antibody (diluted 1:50) was added to the slides. All slides were incubated at $37^{\circ} \mathrm{C}$ for $1 \mathrm{~h}$ and rinsed with PBS. The specimens were incubated in 3,3'-diaminobenzidine tetrahydrochloride solution for $5 \mathrm{~min}$ for color development. Under low magnification, the positive expression of VEGF-intensive regions was observed, and vessels in five fields of view per slide were viewed at a higher magnification (x200). The observation parameters (white balance, aperture, shutter speed and time) were unchanged throughout. Image-Pro Plus software v6.0 was used to save the images, and the integral absorbance (IA) value, as an indicator of VEGF expression, was detected.

Analyses of SOD activity and MDA content. On day 2 postoperatively, 10 tissue specimens $(0.3 \times 0.3 \mathrm{~cm})$ were obtained from section II/III boundaries of each group, weighed, homogenized using a Polytron homogenizer (Janke and Kunkel; IKA, Staufen, Germany) followed by centrifugation at $845.2 \mathrm{x} \mathrm{g}$ for $15 \mathrm{~min}$, and diluted with saline to $10 \%$ ( $\mathrm{vol} / \mathrm{vol})$ in an ice bath. SOD activity was determined using an oxidase enzymatic method, and the MDA level was measured by a method based on the reaction with thiobarbituric acid at $90-100^{\circ} \mathrm{C}$, as previously described (14).

Statistical analysis. The results are expressed as means \pm standard deviations. Statistical evaluation of the data was performed by one-way analysis of variance followed by post hoc comparison test using the least significant difference (equal variances assumed) or Dunnett's T3 (equal variances not assumed) method. All data were analyzed with SPSS software 20.0 (IBM SPSS, Armonk, NY, USA) and graphs were constructed using GraphPad Prism v6.0 (GraphPad Software, 

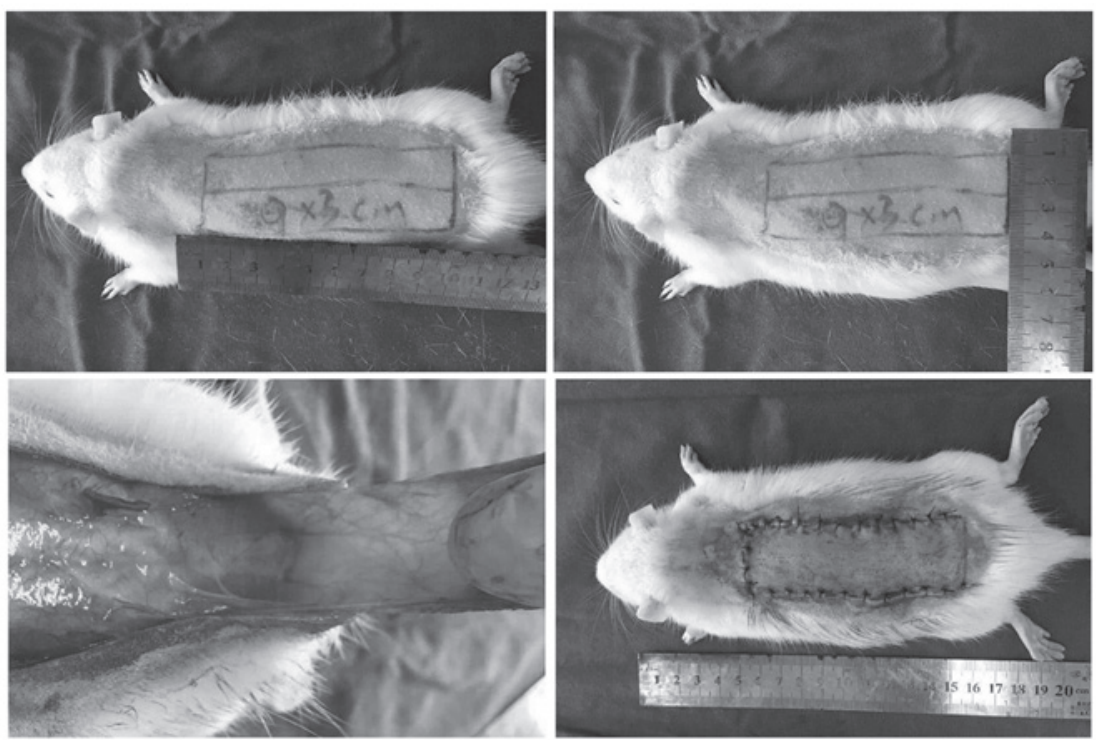

Figure 1. A McFarlane flap model was designed (size, $9 \times 3 \mathrm{~cm}$ ) on the back of each rat and both sacral arteries were systematically sectioned, so that no axial vessels were incorporated into the flap. The flap was separated from the underlying fascia up to its base. After controlling any bleeding, the flap was immediately sutured to the original position with 4-0 running nylon sutures and a wedged cutting needle.

A

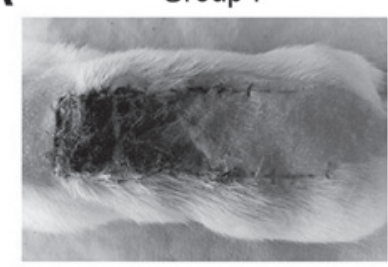

Group II

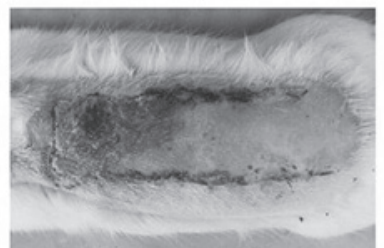

Group III

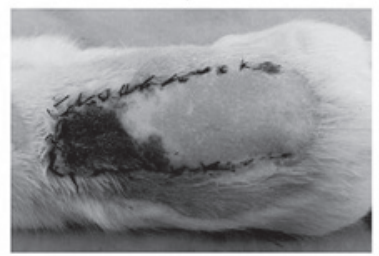

B

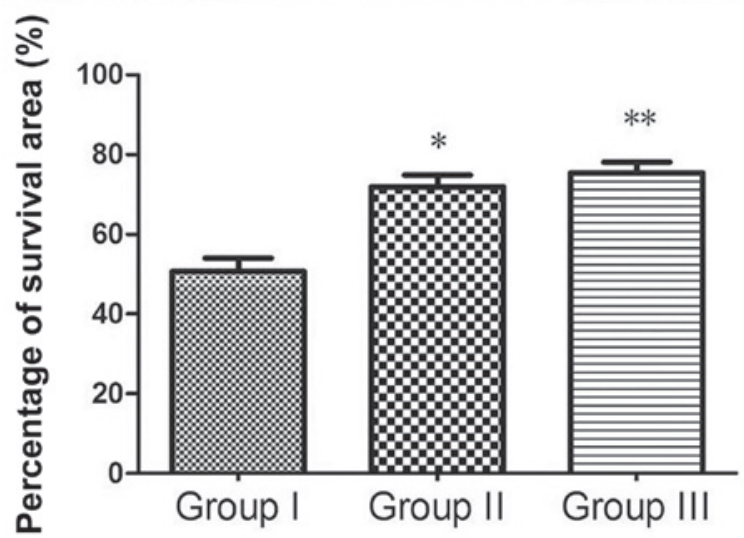

Figure 2. (A) Digital images representative of the skin flaps from the three groups. (B) The percentage of survival area. " $\mathrm{P}<0.05$ vs. group I; ${ }^{* *} \mathrm{P}<0.05$ vs. group II. Group I, control group that was injected with $10 \mathrm{mg} / \mathrm{kg}$ saline once per day; group II, experimental group that was injected with $10 \mathrm{mg} / \mathrm{kg}$ diammonium glycyrrhizinate (DG) once per day; group III, experimental group that was injected with $10 \mathrm{mg} / \mathrm{kg}$ DG twice per day.

Inc., La Jolla, CA, USA). P<0.05 was considered to indicate a statistically significant difference.

\section{Results}

Macroscopic evaluation. On the first postoperative day, the flap pedicles of the three groups were pale, and the distal area (III) was dull red with some small spots exhibiting obvious necrosis. On the seventh day, the necrotic region became darker and tended to fuse, scab and shrink. The boundary between necrotic and surviving parts was clearly visible on each flap.
Surviving flap portions grew tiny hairs. In addition, area I of all of the flaps survived, flaps in area II survived partly, however, area III of all the rats became necrotic. The range of necrosis in the two experimental groups was obviously smaller than that of the control group (Fig. 2A).

Percentage survival area. Seven days after surgery, the mean survival area percentages were $71.983 \pm 7.084 \%$ in group II and $75.373 \pm 6.708 \%$ in group III, which were significantly higher than those in the control group $(50.618 \pm 8.455 \%)$. There was a significant difference in mean survival area between group I 
and II $(\mathrm{P}<0.05)$, and group III exhibited a higher flap survival area than group II ( $\mathrm{P}<0.05$; Fig. $2 \mathrm{~B})$.

Tissue edema. Percentage tissue water contents in groups I, II and III were $57.675 \pm 4.841,51.036 \pm 4.519$ and $49.554 \pm 4.994$, respectively. The percentage tissue water content in group II was significantly lower than that in the control group $(\mathrm{P}<0.05)$. In addition, the water content in group III was significantly lower than that in group II $(\mathrm{P}<0.05)$, indicating that $\mathrm{DG}$ is able to reduce the degree of tissue edema (Fig. 3).

Histology. Seven days after surgery, the flap tissue specimens in area II of the three groups presented differently under the microscope: Acute inflammatory infiltration was apparent in all groups. The infiltration was prominent; $90 \%$ of tissue in the images showed degeneration and necrosis of muscle fibers. However, inflammatory reactions were less severe in the two experimental groups compared with those in the control group (Fig. 4). In area II, the MVD was $19.76 \pm 3.61 / \mathrm{mm}^{2}$, $24.39 \pm 3.21 / \mathrm{mm}^{2}$ and $26.36 \pm 2.89 / \mathrm{mm}^{2}$ for groups I, II and III, respectively (Fig. 5). MVD in group II was significantly higher than that in group I $(\mathrm{P}<0.05)$. Dense neutrophil infiltration was observed in group I (37.91 \pm 3.54$)$, compared with which neutrophil infiltration was decreased significantly in group II $(30.59 \pm 5.39 ; \mathrm{P}<0.05)$. Neutrophil infiltration in group III $(26.52 \pm 4.24)$ was also significantly less than that in group II $(\mathrm{P}<0.05$; Fig. 6). Inflammatory reactions were evaluated according to dense neutrophil infiltration; therefore, the result indicated that the experimental groups had less severe inflammatory reactions on the skin flap when compared with the control group.

VEGF expression. By calculating IA values, the differences in VEGF expression among the three groups were observed (Fig. 7A). The IA of VEGF in group II $(3,056.21 \pm 627.91)$ was higher than that in group I $(2,050.14 \pm 494.97 ; \mathrm{P}<0.05)$. Group III $(3,337.16 \pm 513.29)$ exhibited the highest IA of VEGF among the three groups (Fig. 7B).

SOD activity and MDA content. Forty-eight hours after surgery, the mean SOD activity in group II was $57.605 \pm 4.052 \mathrm{nmol} / \mathrm{mg}$ protein, which was significantly higher than that in the control group $28.740 \pm 5.657 \mathrm{nmol} / \mathrm{mg}$ protein $(\mathrm{P}<0.05)$. The mean SOD of group III was $62.345 \pm 6.329 \mathrm{nmol} / \mathrm{mg}$ protein, significantly higher than that of group II ( $\mathrm{P}<0.05 ;$ Fig. 8$)$. The mean MDA level in group II $(28.444 \pm 9.479 \mathrm{nmol} / \mathrm{mg}$ protein) was significantly less than that in group I $(54.717 \pm 7.644 \mathrm{nmol} / \mathrm{mg}$ protein; $\mathrm{P}<0.05)$. The mean MDA level of group III was $18.446 \pm 8.062 \mathrm{nmol} / \mathrm{mg}$ protein, significantly lower than that of group II $(\mathrm{P}<0.05$; Fig. 9).

\section{Discussion}

Local random pattern skin flap is clinically used in skin and soft issue reconstruction. However, partial necrosis of skin flaps remains common in the postoperative period and causes the surgery to fail. Therefore, it is crucial to prevent partial necrosis in order to enhance survival of the skin flap. Previous studies have found that ischemia-reperfusion injury and inflammation are critical in partial necrosis $(15,16)$. In

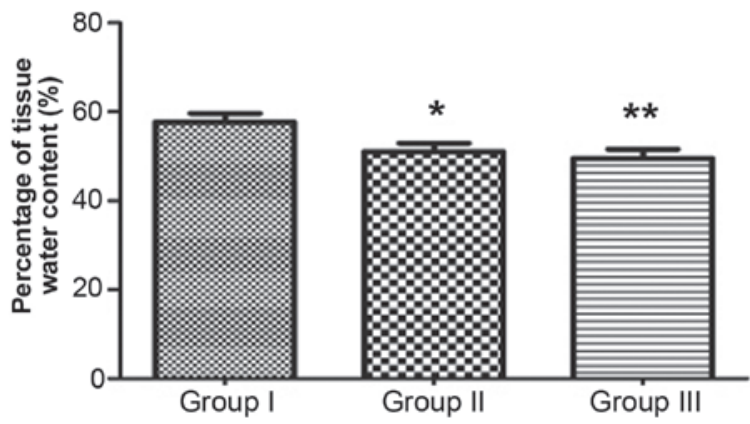

Figure 3. Percentage of tissue water content in the three groups. ${ }^{*} \mathrm{P}<0.05$ vs. group I; ${ }^{* *} \mathrm{P}<0.05$ vs. group II. Group I, control group that was injected with $10 \mathrm{mg} / \mathrm{kg}$ saline once per day; group II, experimental group that was injected with $10 \mathrm{mg} / \mathrm{kg}$ diammonium glycyrrhizinate (DG) once per day; group III, experimental group that was injected with $10 \mathrm{mg} / \mathrm{kg}$ DG twice per day.

addition, certain studies have confirmed that VEGF promotes revascularization $(17,18)$, thus enhancing the survival of skin flaps. Numerous studies have focused on herbal remedies to improve the survival of skin flap by inhibiting ischemia-reperfusion injury, reducing inflammatory reaction and accelerating angiogenesis, with specific examples including Xuebijing, Shuxuetong and Huangqi $(3,19,20)$.

DG is the salt form of glycyrrhetinic acid, which has been widely demonstrated to inhibit inflammation in mice models of liver injury (21-25). Clinically, DG is widely used in the therapy of chronic hepatitis for its effects of inhibiting inflammatory reactions and ischemia-reperfusion injury. These effects have been demonstrated to be beneficial in rat models of ulcerative colitis and cerebral ischemia reperfusion $(7,8)$. The present study focused on its effect on random skin flap survival in rats.

Evidence from the current study demonstrates that DG may improve the survival of a random skin flap in rats. The mean percentages of survival area in the two experimental groups were significantly higher than that of the control group. From general observations of the seventh postoperative day, necrotic regions observed in all three groups had become fused, scabbed and hardened. However, necrotic regions of the experimental groups only existed in flap area III, compared with areas II and III in the control group.

DG may potentially improve flap survival via various mechanisms. It has been reported that venous crisis is more common than arterial crisis following flap surgery (26). If this cannot be treated effectively, flap necrosis is likely to occur. Venous congestion leads to skin swelling and purple discoloration (26). According to the present study, the area of swollen skin in the experimental groups was significantly less than in the control group (by general observation). Furthermore, the percentage tissue water content was identified to be significantly lower in the experimental groups when compared with that in the control group, indicating that DG reduces the degree of tissue edema.

Inflammatory reactions produced by neutrophil accumulation negatively affect random skin flap survival. Bächle et al (27) found that inflammation had an adverse effect on ischemic random-pattern flaps. Previous works demonstrated that NF- $\kappa \mathrm{B}$ is a key molecule in the initiation 

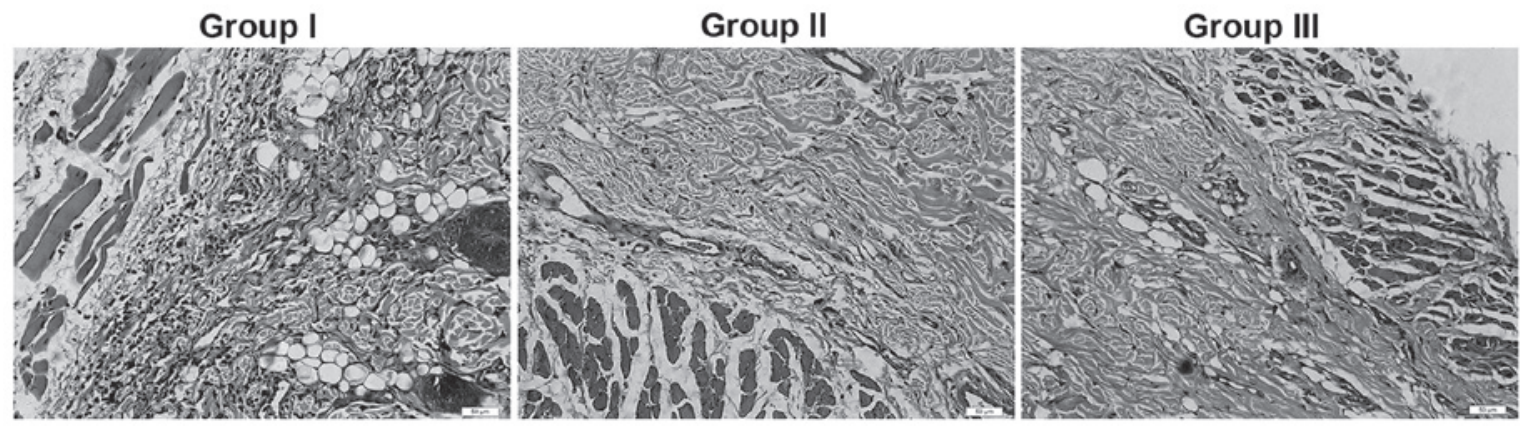

Figure 4. Histological changes in the flaps from the three groups. Tissue sections were stained with hematoxylin and eosin, and observed microscopically (magnification, x200) to detect histological changes. In these images, 90\% of the tissue showed degeneration and necrosis of muscle fibers. The number of vessels in group I was less than that in groups II and III. The neutrophil infiltration in group I was greater than that in groups II and III. Group I, control group that was injected with $10 \mathrm{mg} / \mathrm{kg}$ saline once per day; group II, experimental group that was injected with $10 \mathrm{mg} / \mathrm{kg}$ diammonium glycyrrhizinate (DG) once per day; group III, experimental group that was injected with $10 \mathrm{mg} / \mathrm{kg}$ DG twice per day.

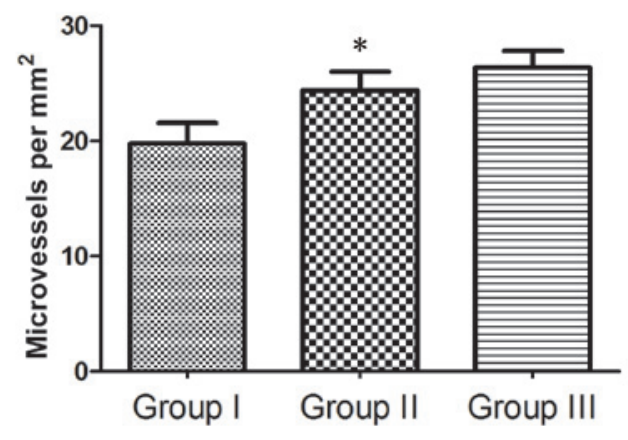

Figure 5. MVD in the three groups. MVD reflects the number of microvessels per unit area $\left(\mathrm{mm}^{2}\right)$. ${ }^{*} \mathrm{P}<0.05$ vs. group I. Group I, control group that was injected with $10 \mathrm{mg} / \mathrm{kg}$ saline once per day; group II, experimental group that was injected with $10 \mathrm{mg} / \mathrm{kg}$ diammonium glycyrrhizinate (DG) once per day; group III, experimental group that was injected with $10 \mathrm{mg} / \mathrm{kg}$ DG twice per day. MVD, microvascular density.

and progression phase of the inflammatory reaction $(28,29)$. In a rat model of ulcerative colitis, the expression of $\mathrm{NF}-\kappa \mathrm{B}$ was inhibited by DG (7). This result indicated that DG was able to reduce neutrophil count and suppress the inflammatory reaction, potentially by reducing the expression of $\mathrm{NF}-\kappa \mathrm{B}$, thus inhibiting the expression of proinflammatory cytokines, adhesive molecules and chemokines. The present study demonstrated that neutrophil density and inflammation were significantly lower in group II compared with group I after observing H\&E-stained slices. Furthermore, neutrophil density in group III was significantly lower than that in group II, indicating that a high dose of DG may be advantageous, with further restriction of the inflammatory reaction.

In addition to the anti-inflammatory effect, the current study determined that DG exerted angiogenesis effects that contributed to increased flap survival. VEGF, an angiogenic growth factor, was previously shown to be an effective agent in reducing skin flap necrosis by increasing angiogenesis and blood supply to the skin flap $(30,31)$. In the present study, the expression level of VEGF was higher in the experimental groups than in the control group. Furthermore, it was found that the MVD in area II of the experimental groups was significantly greater than that of the control group. These results indicate that DG may promote neovascularization

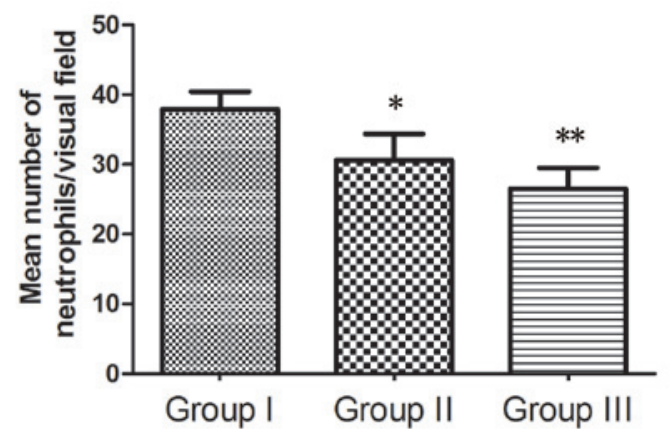

Figure 6. Mean number of neutrophils/visual field (magnification, x100) in the three groups. ${ }^{*} \mathrm{P}<0.05$ vs. group I; ${ }^{* *} \mathrm{P}<0.05$ vs. group II. Group I, control group that was injected with $10 \mathrm{mg} / \mathrm{kg}$ saline once per day; group II, experimental group that was injected with $10 \mathrm{mg} / \mathrm{kg}$ diammonium glycyrrhizinate (DG) once per day; group III, experimental group that was injected with $10 \mathrm{mg} / \mathrm{kg}$ DG twice per day.

and microcirculation in ischemic flaps by increasing VEGF expression, thus enhancing the survival of random skin flaps. However, the detailed mechanism by which DG regulates VEGF expression requires further investigation.

Ischemia-reperfusion injury has been shown to be a primary pathogenic factor causing the necrosis of random skin flaps. During this process, oxygen-delivered free radicals attack the cell membrane and cause lipid peroxidation within the first few minutes of reperfusion (32). Furthermore, accumulation of activated neutrophils in ischemic tissue and activation of xanthine oxidase in endothelial cells induced by reperfusion cause the damage of random skin flaps $(33,34)$. SOD, as an important antioxidase, is the predecessor of $\mathrm{H}_{2} \mathrm{O}_{2}$ and $\mathrm{OH}^{-}$, protecting tissue from injury caused by toxic oxygen-derived free radicals. It is a sensitive indicator of antioxidant status (35). As a product of lipid peroxidation, MDA indirectly reflects the extent of tissue damage due to ischemia-reperfusion injury (36). In the present study, mean SOD activity in the experimental groups were significantly higher than those in the control group. However, the mean MDA levels in the experimental groups were lower than those in the control group. It was also found that a higher dose of DG had greater beneficial effects on the mean SOD activity and mean MDA level. These results indicated that DG protects the 
A

Group I

Group II

Group III

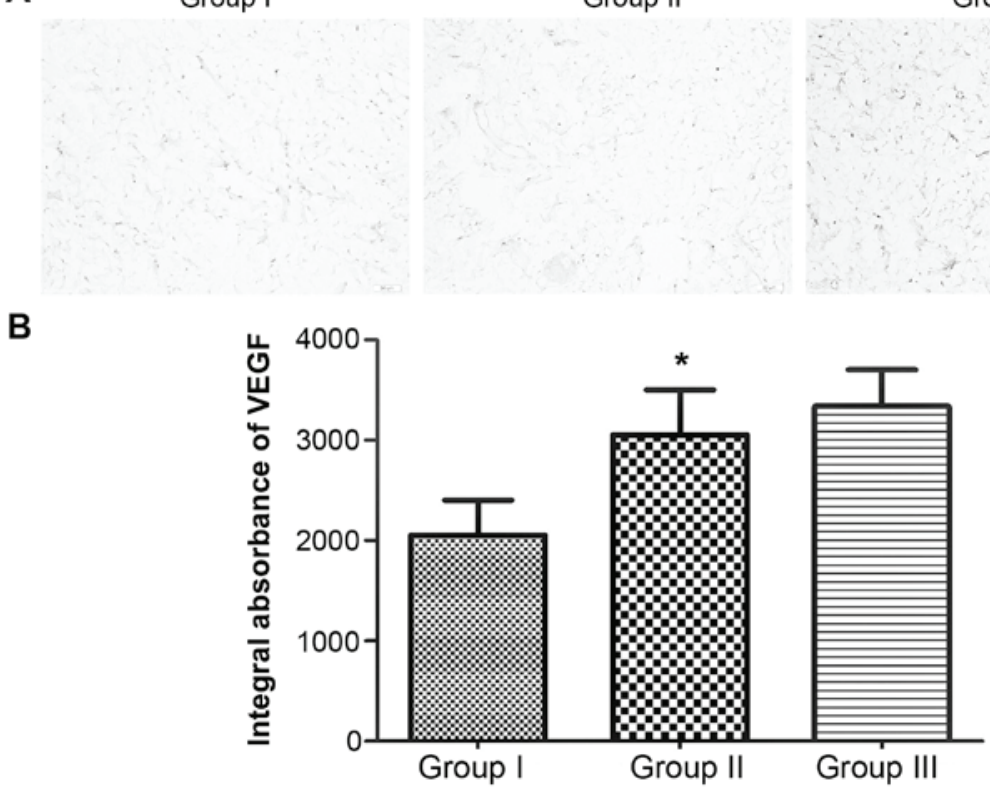

Figure 7. (A) Comparison of VEGF expression in the intermediate areas (area II) of the three groups. The sections were observed under a microscope (magnification, x200). The levels of VEGF expression in vessels and stromal cells in groups II and III were significantly higher than those in group I. (B) The mean IA of VEGF in the three groups. "P $<0.05$ vs. group I. Group I, control group that was injected with $10 \mathrm{mg} / \mathrm{kg}$ saline once per day; group II, experimental group that was injected with $10 \mathrm{mg} / \mathrm{kg}$ diammonium glycyrrhizinate (DG) once per day; group III, experimental group that was injected with $10 \mathrm{mg} / \mathrm{kg}$ DG twice per day. VEGF, vascular endothelial growth factor; IA, integral absorbance.

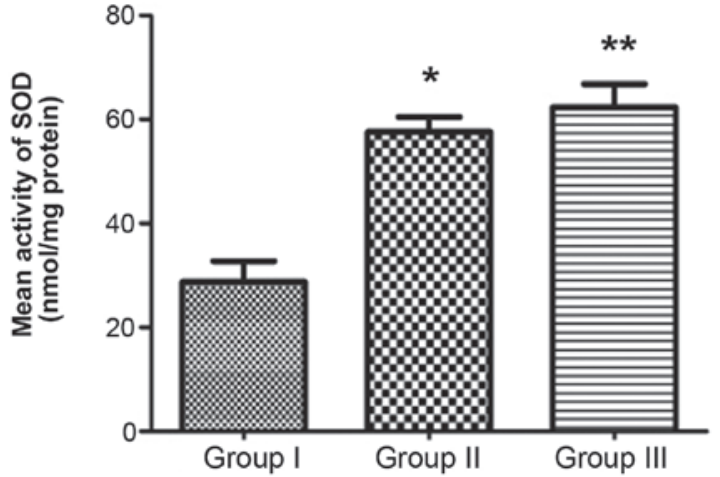

Figure 8. Mean SOD activity in the three groups. ${ }^{*} \mathrm{P}<0.05$ vs. group $\mathrm{I} ;{ }^{* *} \mathrm{P}<0.05$ vs. group II. Group I, control group that was injected with $10 \mathrm{mg} / \mathrm{kg}$ saline once per day; group II, experimental group that was injected with $10 \mathrm{mg} / \mathrm{kg}$ diammonium glycyrrhizinate (DG) once per day; group III, experimental group that was injected with $10 \mathrm{mg} / \mathrm{kg}$ DG twice per day. SOD, superoxide dismutase.

tissue from damage caused by ischemia-reperfusion injury in a dose-dependent manner.

In conclusion, in the present study, DG successfully improved the survival of random skin flaps in rats. The areas of necrosis were significantly smaller in the experimental groups compared with the control group. The effects of DG correlated well with the histological and immunohistochemical findings of increased VEGF expression level and promoted neovascularization. Furthermore, the anti-inflammatory and antioxidant effects of DG were associated with improved skin flap survival. Additionally, DG was identified to exert a dose-dependent effect on promoting the survival of random skin flap in rats, which also demonstrated the beneficial effect of DG. These

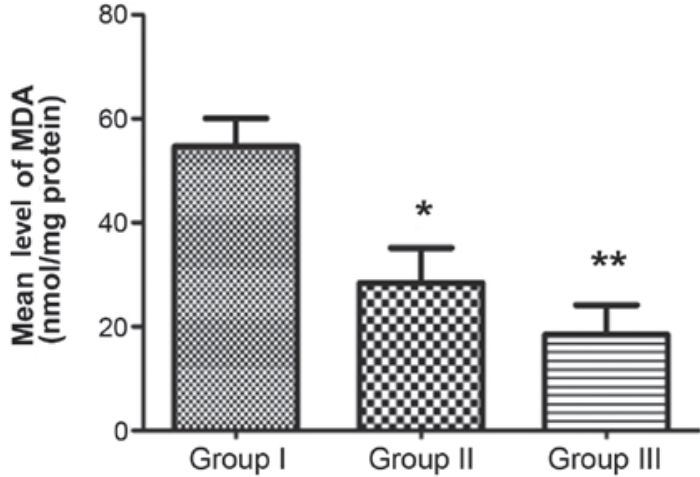

Figure 9. Mean MDA level in the three groups. " $\mathrm{P}<0.05$ vs. group I; ${ }^{* * *} \mathrm{P}<0.05$ vs. group II. Group I, control group that was injected with $10 \mathrm{mg} / \mathrm{kg}$ saline once per day; group II, experimental group that was injected with $10 \mathrm{mg} / \mathrm{kg}$ diammonium glycyrrhizinate (DG) once per day; group III, experimental group that was injected with $10 \mathrm{mg} / \mathrm{kg}$ DG twice per day. MDA, malondialdehyde.

results provide a novel therapeutic approach to improve the survival of random skin flaps. However, further clinical studies are required to fully understand the benefits and limitations of DG in the treatment for humans.

\section{Acknowledgements}

The present study was supported by the Xinmiao talent plan of Zhejiang Province (grant no. 2015R413005), Zhejiang Province Chinese medicine scientific research fund (grant no. 2014ZB074), the National Natural Science Foundation of China (grant no. 81503397), and the Zhejiang provincial medical and health science and technology program (grant no. 2016KYB195). 


\section{References}

1. Yang M, Sheng L, Li H, Weng R and Li QF: Improvement of the skin flap survival with the bone marrow-derived mononuclear cells transplantation in a rat model. Microsurgery 30: 275-281, 2010.

2. Kim HJ, Xu L, Chang KC, Shin SC, Chung JI, Kang D, Kim SH, Hur JA, Choi TH, Kim S, et al: Anti-inflammatory effects of anthocyanins from black soybean seed coat on the keratinocytes and ischemia-reperfusion injury in rat skin flaps. Microsurgery 32: 563-570, 2012.

3. Bin C, Dingsheng L, Leyi C, Bin L, Yuting L, Liren W and Zhijie L: Beneficial effects of Xuebijing injection on random skin flap survival in rats. J Surg Res 196: 421-426, 2015.

4. Cao B, Wang L, Lin D, Cai L and Gao W: Effects of lidocaine on random skin flap survival in rats. Dermatol Surg 41: 53-58, 2015

5. van Rossum TG, Vulto AG, de Man RA, Brouwer JT and Schalm SW: Review article: Glycyrrhizin as a potential treatment for chronic hepatitis C. Aliment Pharmacol Ther 12: 199-205, 1998

6. Iino S, Tango T, Matsushima T, Toda G, Miyake K, Hino K, Kumada H, Yasuda K, Kuroki T, Hirayama C, et al: Therapeutic effects of stronger neo-minophagen $\mathrm{C}$ at different doses on chronic hepatitis and liver cirrhosis. Hepatol Res 19: 31-40, 2001.

7. Yuan H, Ji WS, Wu KX, Jiao JX, Sun LH and Feng YT: Anti-inflammatory effect of Diammonium Glycyrrhizinate in a rat model of ulcerative colitis. World J Gastroenterol 12 : 4578-4581, 2006.

8. Hou SZ, Li Y,Zhu XL, Wang ZY, Wang X and Xu Y: Ameliorative effects of diammonium glycyrrhizinate on inflammation in focal cerebral ischemic-reperfusion injury. Brain Res 1447: 20-27, 2012.

9. Mandriota SJ, Pyke C, Di Sanza C, Quinodoz P, Pittet B and Pepper MS: Hypoxia-inducible angiopoietin-2 expression is mimicked by iodonium compounds and occurs in the rat brain and skin in response to systemic hypoxia and tissue ischemia. Am J Pathol 156: 2077-2089, 2000.

10. Kelly CP, Gupta A, Keskin M and Jackson IT: A new design of a dorsal flap in the rat to study skin necrosis and its prevention. J Plast Reconstr Aesthet Surg 63: 1553-1556, 2010.

11. Ren H, Lin D, Mou Z and Dong P: The adverse effect of selective cyclooxygenase-2 inhibitor on random skin flap survival in rats PLoS One 8: e82802, 2013

12. Chen Y, Tong H, Zhang X, Tang L, Pan Z, Liu Z, Duan P and Su L: Xuebijing injection alleviates liver injury by inhibiting secretory function of Kupffer cells in heat stroke rats. J Tradit Chin Med 33: 243-249, 2013

13. Yamaguchi $S$, Watanabe $G$, Tomita $S$ and Tabata $S$ : Lidocaine-magnesium blood cardioplegia was equivalent to potassium blood cardioplegia in left ventricular function of canine heart. Interact Cardiovasc Thorac Surg 6: 172-176, 2007.

14. Liu L, Liu Y, Cui J, Liu H, Liu YB, Qiao WL, Sun H and Yan CD: Oxidative stress induces gastric submucosal arteriolar dysfunction in the elderly. World J Gastroenterol 19: 9439-9446, 2013.

15. Coskunfirat OK, Cinpolat A, Bektas G, Ogan O and Taner T: Comparing different postconditioning cycles after ischemia reperfusion injury in the rat skin flap. Ann Plast Surg 72: 104-107, 2014.

16. Xu R, Ge J, Lei Y and Lu X: Improvement effect of estrogen on flap reperfusion injury and blood supply. Zhongguo Xiu Fu Chong Jian Wai Ke Za Zhi 23: 964-968, 2009 (In Chinese).

17. Zhang F and Lineaweaver W: Acute and sustained effects of vascular endothelial growth factor on survival of flaps and skin grafts. Ann Plast Surg 66: 581-582, 2011.

18. Zhang F, Fischer K, Komorowska-Timek E, Guo M, Cui D, Dorsett-Martin W, Buncke HJ and Lineaweaver WC: Improvement of skin paddle survival by application of vascular endothelial growth factor in a rat TRAM flap model. Ann Plast Surg 46: 314-319, 2001.
19. Cai L, Cao B and Lin D: Effects of Traditional Chinese Medicine Huangqi Injection (Radix astragali) on Random Skin Flap Survival in Rats. J Reconstr Microsurg 31: 565-570, 2015.

20. Cai L, Huang W and Lin D: Effects of traditional Chinese medicine Shuxuetong injection on random skin flap survival in rats. Sci World J 2014: 816545, 2014.

21. Tang B, Qiao H, Meng F and Sun X: Glycyrrhizin attenuates endotoxin- induced acute liver injury after partial hepatectomy in rats. Braz J Med Biol Res 40: 1637-1646, 2007.

22. Abe K, Ikeda T, Wake K, Sato T, Sato T and Inoue H: Glycyrrhizin prevents of lipopolysaccharide/D-galactosamine-induced liver injury through down-regulation of matrix metalloproteinase-9 in mice. J Pharm Pharmacol 60: 91-97, 2008.

23. Tsuruoka N, Abe K, Wake K, Takata M, Hatta A, Sato T and Inoue $\mathrm{H}$ : Hepatic protection by glycyrrhizin and inhibition of iNOS expression in concanavalin A-induced liver injury in mice. Inflamm Res 58: 593-599, 2009.

24. Yoshida T, Abe K, Ikeda T, Matsushita T, Wake K, Sato T, Sato T and Inoue H: Inhibitory effect of glycyrrhizin on lipopolysaccharide and d-galactosamine-induced mouse liver injury. Eur J Pharmacol 576: 136-142, 2007.

25. Lee CH, Park SW, Kim YS, Kang SS, Kim JA, Lee SH and Lee SM: Protective mechanism of glycyrrhizin on acute liver injury induced by carbon tetrachloride in mice. Biol Pharm Bull 30: 1898-1904, 2007.

26. Yingxin G, Guoqian Y, Jiaquan L and Han X: Effects of natural and recombinant hirudin on VEGF expression and random skin flap survival in a venous congested rat model. Int Surg 98: 82-87, 2013.

27. Bächle AC, Mörsdorf P, Rezaeian F, Ong MF, Harder Y and Menger MD: N-acetylcysteine attenuates leukocytic inflammation and microvascular perfusion failure in critically ischemic random pattern flaps. Microvasc Res 82: 28-34, 2011.

28. Neurath MF, Fuss I, Schürmann G, Pettersson S, Arnold K, Müller-Lobeck H, Strober W, Herfarth C and Büschenfelde KH: Cytokine gene transcription by NF-kappa B family members in patients with inflammatory bowel disease. Ann N Y Acad Sci 859 (1 INTESTINAL PL): 149-159, 1998.

29. Blackwell TS and Christman JW: The role of nuclear factor-kappa B in cytokine gene regulation. Am J Respir Cell Mol Biol 17: 3-9, 1997.

30. Vourtsis SA, Spyriounis PK, Agrogiannis G, Papalois A and Ionac M: Does VEGF have an effect on the survival of a long random skin flap by its application at the recipient area? Chirurgia (Bucur) 107: 494-500, 2012.

31. Fang T, Lineaweaver WC, Chen MB, Kisner C and Zhang F: Effects of vascular endothelial growth factor on survival of surgical flaps: A review of experimental studies. J Reconstr Microsurg 30: 1-13, 2014.

32. Braunersreuther V and Jaquet V: Reactive oxygen species in myocardial reperfusion injury: From physiopathology to therapeutic approaches. Curr Pharm Biotechnol 13: 97-114, 2012.

33. Ozkan F, Senayli Y, Ozyurt H, Erkorkmaz U and Bostan B: Antioxidant effects of propofol on tourniquet-induced ischemia-reperfusion injury: An experimental study. J Surg Res 176: 601-607, 2012.

34. Cui J, Liu L, Zou J, Qiao W, Liu H, Qi Y and Yan C: Protective effect of endogenous hydrogen sulfide against oxidative stress in gastric ischemia-reperfusion injury. Exp Ther Med 5: 689-694, 2013.

35. SirotaTV,Zakharchenko MV and Kondrashova MN: Cytoplasmic superoxide dismutase activity is a sensitive indicator of the antioxidant status of the rat liver and brain. Biomed Khim 60: 63-71, 2014 (In Russian).

36. Sun L, Li Y, Shi J, Wang X and Wang X: Protective effects of ligustrazine on ischemia-reperfusion injury in rat kidneys. Microsurgery 22: 343-346, 2002. 